\title{
Variação: a coda [R] em Santa Catarina, Brasil
}

\author{
Teresinha de Moraes Brenner ${ }^{1}$ \\ Universidade Federal de Santa Catarina
}

\section{Résumé}

Cet article présente une succincte discussion à propos de la vibrante, coda syllabique, dans le dialecte des pêcheurs de Florianópolis, S.C. Un /R/, liquide dorsal, s'est introduit, dans le XIX ${ }^{\text {éme }}$ siècle dans la région de colonisation des Açores et il a eu une évolution parallèle à celle de la liquide coronale apicale introduite précédemment par le portugais continental et celui des Iles. Aujourd'hui, la coda vibrante se montre très fréquemment comme une fricative dorsale. Ce travail délimite deux processus locaux: l'enchaînement et la gémination. Il faut, alors, revoir la syllabe métrique, les échelles de sonorité, les propriétés phonémiques qui impliquent la resyllabation de $/ \mathrm{R} /$. La phonologie multilinéaire en co-articulation avec les principes fondamentaux de la phonétique accoustique permettent d'expliquer ces phénomènes dialectaux. 
borda-se a variação lingüística como um fenômeno expressivo da oralidade, implicando o sistema fonológico abstrato da língua relacionado ao quadro fonético da realidade concreta da fala. Discutem-se dois processos da coda silábica [R], vibrante [dorsal], em Santa Catarina, Brasil: o encadeamento e a geminação que a inserem, respectivamente, como uma batida [coronal] e uma vibrante [dorsal] no sistema das líquidas. Vibrante e batida constituem segmentos aparentados na sua formação histórica e na sua estrutura fonêmica, representando uma classe natural restrita e bem definida. Limita-se o campo da ilustração ao dialeto dos pescadores de Florianópolis.

A análise faculta uma interface entre a fonética e a fonologia, pela articulação de um modelo da fonologia multilinear tridimensional e de recursos da informática postos a serviço da fonética acústica. Utilizou-se, para a elaboração de espectogramas e sonagramas, um computador PC, programa UNICE, e um computador Macintosh II, programa Audiomedia (registro) e Signalize (Sistema Designer), ambos do ILPGA de Paris III, Sorbonne Nouvelle. O corpus foi colhido para Tese de Doutorado da autora, sendo completado e corroborado por posteriores pesquisas de campo realizadas por alunos do Curso de Letras da Graduação da UFSC, sob orientação da professora.

$\mathrm{O}$ artigo focaliza, pois, dois processos de coda [R] pertencentes a uma gramática dialetal, inserida no litoral pesqueiro da Ilha de Florianópolis e que convive paralelamente com uma gramática padrão, de cunho culto, preservada pelo Ensino e Órgãos Oficiais e disseminada pela mídia. Introduzem, assim, os fenômenos em estudo parâmetros locais condizentes com postulados mais amplos da língua portuguesa e princípios da gramática universal. 
A categoria ponto de articulação compreende, segundo Clements (1993), quatro subcategorias: [labial] (segmento bilabial e labiodental), [coronal] (alveolar, alveopalatal, palatal), [dorsal] (velar, uvular) e [radical] (faringal, laringal, glotal). A abordagem da coda [dorsal] de Santa Catarina corresponde, pois, a um /R/ vibrante de natureza uvular ou velar, pertencente à gramática regional, recobrindo diferentes classes sociais e grupos particulares, como a categoria dos pescadores e rendeiras.

$\mathrm{Na}$ atualidade, a vibrante dorsal [R], uma líquida, dominante na gramática dialetal, comporta variantes líquidas e fricativas. Quanto às origens desse fonema na região, o quadro histórico o delimita nos

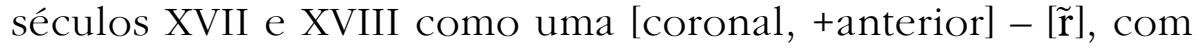
articulação alveolar. Esse segmento foi introduzido pelos colonizadores portugueses do continente e das ilhas açorianas. O falar açoriano atual apresenta um sistema restrito de velares, o que favorece o argumento de que a colonização se fez pelo elemento apical. As modificações fizeram-se notar somente no século XIX, sob influência da metrópole e dos portos mais importantes, como o do Rio de Janeiro. O processo articulatório de formação da [coronal], envolvendo o ápice da língua e sua região dorsal, evoluiu, devido a fatores histórico-culturais, para um recuo do fonema na cavidade bucal, com tendência a fricção (FURLAN, 1989, p. 124-6, apud BRENNER, 1996).

No eixo sincrônico, conforme o exposto, a vibrante, na posição de ataque e de coda silábica, comporta-se, entre os pescadores de Florianópolis, como [coronal], remontando às raízes coloniais mais antigas, e, na maioria dos casos, como [dorsal]. Nesse último registro, a variação da coda, de que trata este estudo, oscila entre a líquida [dorsal][+sonora] (velar e uvular), e a fricativa [dorsal], portadora dos traços contextuais [ \pm sonora] e a [glotal], tendo as duas últimas grande incidência, sobretudo, em final de vocábulo.

Segundo Malmberg (1954), a vibrante uvular resulta da vibração da úvula, produzindo contatos repetidos com a parte posterior do dorso da língua. Na alveolar, a corrente de ar empurra a ponta da língua contra os alvéolos e, graças à elasticidade desse articulador, 
ele regressa à posição original, repetindo o movimento quatro ou cinco vezes. A realização anterior e recuada da vibrante é percebida pelo autor como variantes de um mesmo fonema em português, inglês, francês e alemão. Essa é a posição assumida por Oliveira \& Brenner (1988) e por Furlan (apud BRENNER, 1996) para a descrição do /R/ [dorsal] de Santa Catarina que se alterna com o [coronal]. Bonnard (1982, p. 10) também interpreta a uvular do francês como resultante de batidas da úvula.

Exemplifica-se, para confronto, através de dois sonagramas, a coda [dorsal] líquida e a fricativa [-sonora], omitindo-se a ocorrência de menor freqüência, da [coronal]. Sejam:
(1)
(a) ['perne] (J.J.M.)
(b) ['baxku] (J.J.M.)
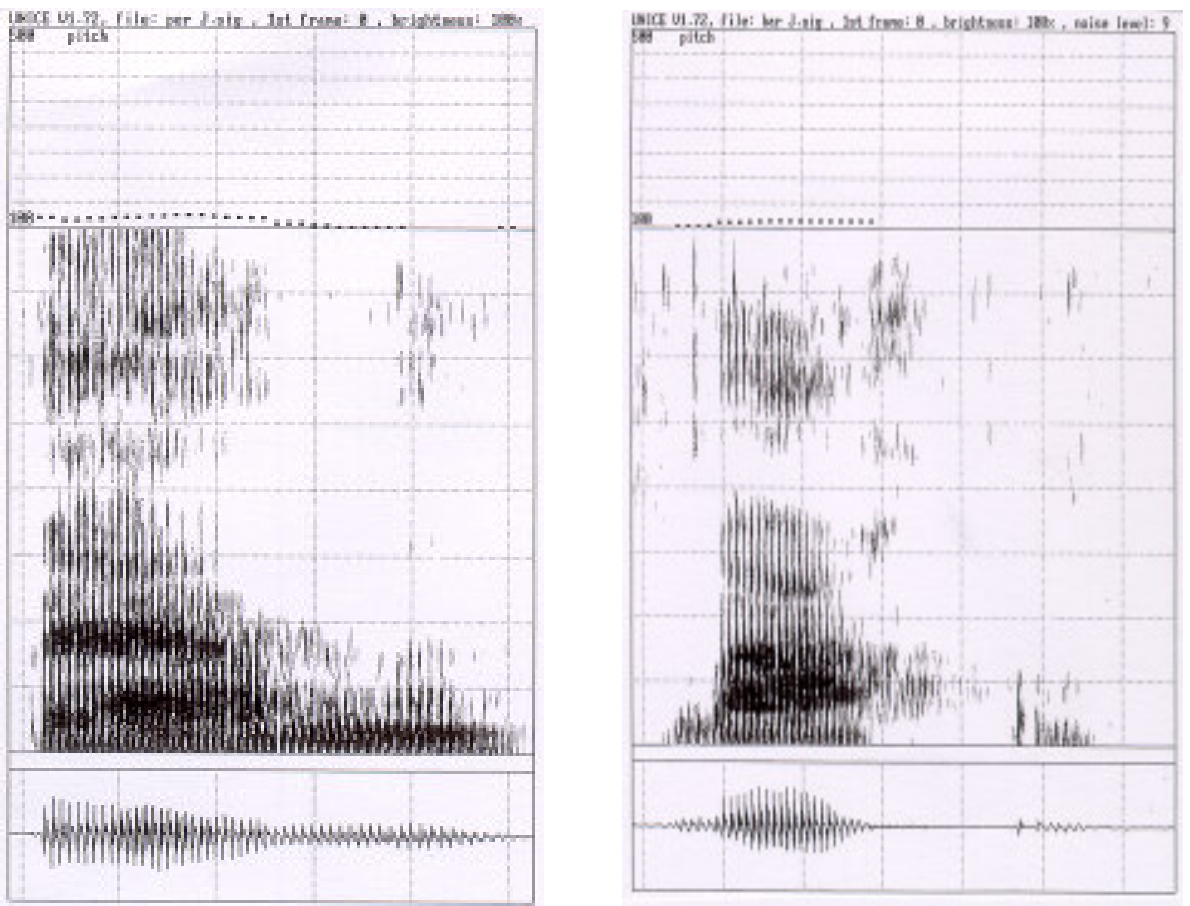
No primeiro exemplo, a coda vibrante configura-se como uma líquida formântica - dorsal. No segundo, a variante mostra-se como uma fricativa dorsal surda, que evidencia pouca turbulência, nenhuma sonoridade. Sua posição intravocabular implica o processo assimilatório da esquerda para a direita, com comando da consoante surda do ataque silábico que a segue, formando um contexto de duas consoantes [-son]. O fenômeno acusa um fechamento do grau de abertura da coda [dorsal].

Alude-se à realização fricativa para confirmar a diversidade variacional da coda vibrante. Mas, na verdade, pretende-se descrever, neste estudo, a inserção da vibrante no sistema das líquidas, com breve alusão a suas variantes livres fricativas. Cada classe fonêmica corresponde a um determinado grau de abertura e sonoridade, implicando procedimentos articulatórios com efeitos acústicos particulares. Constituem, ainda, variáveis pertinentes para análise a estrutura intrínseca do fonema, o padrão silábico em que se insere, bem como a posição desse no vocábulo e na frase.

A escala da sonoridade proposta por Milliken, 1988, inspirado em Clements, 1988 (apud BRENNER, 1996, p.448), confere às líquidas o grau mais elevado de sonoridade entre as consoantes. Veja-se:

(2) Escala da sonoridade

\begin{tabular}{|c|c|c|c|c|c|}
\hline $\mathrm{O}$ & $\mathrm{N}$ & $\mathrm{L}$ & G & $\mathrm{V}$ & \\
\hline- & - & - & - & + & [aberto] \\
\hline- & - & - & + & + & [vocóide] \\
\hline- & - & + & + & + & [aproximante] \\
\hline- & + & + & + & + & [sonante] \\
\hline 0 & 1 & 2 & 3 & 4 & escala da sonoridade \\
\hline
\end{tabular}

A consoante líquida (uma sonante, aproximante) apresenta grau máximo- 2 de sonoridade. A fricativa, variante da vibrante líquida, como obstruente, restringe-se a grau zero. Ocorre, pois, no processo variacional de $/ \mathrm{R} /$ de vibrante para fricativa um fortalecimento ou fechamento consonântico. 
Brenner (1996, p.557) traça uma escala de sonoridade para as líquidas do português, apoiada no cruzamento de três variáveis: modo e ponto de articulação relacionados a padrões silábicos. A nomenclatura batida (tepe) remete a uma tradução direta do inglês tape do francês battement. O termo tem sido usado em publicações por fonólogos da UFSC de Florianópolis desde a década de 1980. Confrontem-se as posições da batida e da vibrante:

\begin{tabular}{|c|ccccccc|}
\hline Modo & \multicolumn{7}{|c|}{ Ponto } \\
\hline 1 & 1 & 2 & 3 & 4 & 5 & 6 & 7 \\
Vibrante & {$[\mathrm{r}] \mathrm{V}$} & $\mathrm{V}[\mathrm{r}] \mathrm{V}$ & & $(\mathrm{C}) \mathrm{V}[\mathrm{r}]$ & {$[\mathrm{R}] \mathrm{V}$} & $\mathrm{V}[\mathrm{R}] \mathrm{V}$ & $\mathrm{V}[\mathrm{R}]$ \\
2 & & & & & & & \\
Batida & & $\mathrm{V}[\mathrm{r}] \mathrm{V}$ & $\mathrm{C}[\mathrm{r}] \mathrm{V}$ & & & \\
\hline
\end{tabular}

Observa-se que o quadro (3) distribui as líquidas, no eixo vertical (grau de abertura e sonoridade de categorias relativas a modo de articulação). Situa a vibrante como a menos sonora, seguida, num crescendo, da batida e coloca a lateral, não mencionada no esquema acima, no grau mais elevado da escala. No eixo horizontal, a posição "6" - intervocalidade e recuo de /R/ - evidencia-se como altamente sonora e aberta, comportando uma co-articulação com a vogal precedente e a seguinte. A "4" e, sobretudo, a "7" , relativas a padrão silábico, facultam a vocalização em [y] e [w]. A descrição que acaba de ser feita implica a premissa defendida pela autora de que a vibrante [coronal] representa um fonema mais fechado que a [dorsal]. Na verdade, a gradação da abertura e sonoridade dos fonemas no eixo horizontal (ponto de articulação na cavidade bucal) merece, ainda, revisão.

Jakobson (BRENNER, 1996) insere vogais e consoantes oclusivas surdas num modelo triangular, classificação baseada no atributo altura, alta x baixa energia no espectro. Coloca no ápice da figura a $\operatorname{vogal} / \mathrm{a} /$, portadora de energia concentrada e elevada, como o fonema mais sonoro e aberto do sistema. A base é ocupada pelas difusas /i/, de tonalidade aguda, e /u/, grave. Numa reduplicação do triângulo, na mesma posição da vogal compacta, ou seja, no cume, coloca a 
velar / k/, opondo-se a /p/ e /t/, elementos com difusão de energia, nas baixas e altas freqüências do espectro, respectivamente. Articulatoriamente, o fonema compacto resulta da forma e do volume da cavidade bucal. Autores como Sievers, Jespersen, Foley, (CLEMENTS, 1988) também fazem referência à abertura da cavidade bucal como parâmetro para organização das escalas de sonoridade.

Segundo o exposto, pressupõe-se que a vibrante [dorsal] seja, intrinsecamente, mais aberta e sonora que a [ coronal, +anterior]. A configuração formântica compactada da líquida [dorsal] se opõe à organização da [coronal] que implica uma seqüência de três, quatro ou mais batidas breves, possuindo cada uma seus formantes individualizados. Nesse sentido, o sonagrama da [dorsal] se aproxima mais ao da vogal.

Remete-se, novamente, às variáveis em estudo- padrão silábico versus ponto e modo de articulação. Retome-se a vibrante. A posição "2" e a "6" correspondem à de ataque silábico em intervocalidade. A vibrante líquida, nesse contexto, recebe propriedades vocálicas no processo assimilatório, co-articulação à direita e à esquerda, o que lhe confere alto grau de sonoridade e abertura, sem perda, no entanto, do traço consonântico. O padrão com coda fornece outra leitura. No núcleo, situa-se o elemento mais aberto e sonoro da sílaba, a vogal. $\mathrm{O}$ ataque contém os elementos em crescendo e a coda constitui o travamento, com diminuição de abertura e sonoridade. A coarticulação vocálica se faz somente à esquerda com forte interferência na consoante final. Por conseguinte, conforme referência supracitada, apenas a coda pode se vocalizar, num processo de enfraquecimento consonântico.

No português padrão, a batida não assume a função de coda, realização restrita a alguns sistemas regionais. Situa-se, geralmente, no ataque intervocálico e figura como segundo elemento do encontro consonantal. Constitui fonema do português, detendo propriedades que the são peculiares, o que the permite comutar, em posição intervocálica no quadro das líquidas, com a vibrante e a lateral e, no encontro consonantal, com a lateral [coronal]. Quanto 
à sua origem na língua, segundo literatura mais corrente, provém da vibrante múltipla, não constando no quadro do latim clássico.

No latim clássico, o $/ \mathbf{r}$ / caracterizava-se como uma vibrante prépalatal, resultante de vibrações da ponta da língua no verso da arcada dentária superior, identificando-se como um ruído árido(TERENCIANO, apud FARIA, 1957, p. 105). Vários gramáticos da época fizeram referência à semelhança do efeito acústico do segmento com o rosnar de um cão. Prisciano (id. ibid) lembra que, no grego, o $/ \mathbf{r} /$ era aspirado, mas não no latim. A intervocalidade lhe facultava a geminação. Estudando a origem do [R] francês, Bonnard (1982, p.10) afirma que o latino era apical e roulé, vibrando a ponta da língua contra os alvéolos superiores.

A duração particularizou um traço vocálico do latim clássico. Aplicada à consoante, gerou a geminada. Ilari (1992, p. 82) a interpreta como uma consoante longa dando "a impressão" de dois segmentos. Alude ao fato de que toda geminada implicava uma sílaba antecedente travada. Essa interpretação vem de encontro à proposição da teoria auto-segmental que concebe duas posições abstratas para a realização de um único segmento na estrutura de superfície. O autor (p.77) apresenta, para o latim, um sistema de 17 consoantes. Excluídas duas semivogais, duas labiovelares (portadoras de articulação secundária) e uma glotal, as demais comportavam uma geminada. A vibrante simples classifica-se no quadro como dental. A distinção entre a simples e a geminada manteve-se no latim vulgar, eliminando-se as duplas apenas no Período Romano que começou com a queda do Império no século $\mathrm{V}$ d.C. Sustentaram, na atualidade, o traço apenas o sardo e o italiano. (id., p. 77-83).

A realização da geminada latina em duas sílabas contíguas é ilustrada por Bonnard (1982, p. 31) na vocalização de [l/1] em [w] e [u] com timbre velar, em francês, a partir do século VII ao XVI, como em bèllus: bèllus $>$ bels $>$ beaus.

No quadro traçado por Silva (1996, p.77) relativo ao latim clássico, a autora apresenta doze geminadas, ficando a vibrante simples alinhada junto à longa. Mostra (p. 78) que a geminada latina 
derivou a vibrante (múltipla)[R] do português: ferru $>$ ferro. No sistema do galego-português (primeira fase do período arcaico) já estão registradas as vibrantes múltipla e simples, com ilustração através de 'ferro', / $\tilde{\mathbf{r}} /$ comutando com 'fero', / $/$ /, dois fonemas distintos, ambos alveolares (id. p. 88).

Mattoso Câmara (1977, p. 78-9) defendeu, inicialmente, para a vibrante forte do português atual, uma geminação consonântica, hipótese posteriormente por ele eliminada, só reconhecendo o processo na juntura. Esse $\tilde{\mathbf{r}} /$ forte possuiria uma variante posicional, o brando. Essa última proposição foi também abandonada, postulando o autor, para o português, duas vibrantes comutáveis em posição intervocálica: a múltipla e a simples. Estabelece a diferença entre a primeira e a última por ter essa resguardado a articulação alveolar, enquanto a múltipla se manifestou por um recuo na cavidade bucal. A posição inicial, bem como a medial não-intervocálica, particularizam o elemento forte. Comenta (p.78), ainda, a existência de uma 'cumulação' no segmento pós-vocálico entre o forte e o brando.

A existência da geminação no português só é identificada no processo de juntura. Mattoso Câmara cita o exemplo em que contrapõe ar roxo /ãr̃̃oxu/e arrocho /ar̃oxu/com implicações no esquema acentual (CÂMARA JR., 1977, p. 79).

O estudo de Mattoso Câmara (1975, p. 52) conclui que a vibrante /rr/ do latim clássico, após ter perdido a geminação, preservou propriedades particulares de /r/ forte de vibração múltipla, não se identificando com o chamado $/ \mathrm{r} /$ simples intervocálico. $\mathrm{O}$ /r/ brando derivou da lenização do último. A vibrante múltipla permaneceu nas posições inicial e medial. Segundo o exposto, o /r/ geminado e o simples forte do latim deram origem às atuais líquidas do quadro do português: vibrante, inicialmente apenas alveolar, e batida.

Restringe-se este artigo, conforme objetivo supramencionado, a apenas dois fenômenos concernentes à vibrante como coda silábica: o encadeamento e a geminação. Ambos a limitam ao quadro das líquidas. O primeiro, na escala (3), desloca-a da posição "7" da 
vibrante, coda silábica, para a posição "2" do sistema da batida. Isso significa que, na juntura, a coda vibrante se realiza, num processo quase generalizado de ressilabação, como uma batida, inserida na posição de ataque intervocálico e intervocabular.

O modelo multilinear tridimensional de Encrevé (1988) prevê três níveis na representação fonológica: o silábico, o esqueletal e o segmental. Decompondo-se a sílaba métrica em ataque e rima, a coda delineia-se na última, alinhada com o núcleo. No processo de encadeamento, a coda é representada na base por uma vibrante em final de vocábulo, num esquema "(C)VC", ressilabando à direita e tornando-se uma batida intervocálica associada ao ataque vazio do vocábulo seguinte. Desaparece a coda vibrante "C" e impõe-se o esquema "VCV" no qual "C" se qualifica como batida em posição de ataque silábico. Exemplifique-se:
(4)
Dialeto
Português "standard"
(J.L.)
(a) [botara'b $\left.\tilde{\mathfrak{e}}^{\mathrm{p}} \mathrm{ke}\right]$
[bo'tar a'b $\tilde{e}^{\mathfrak{y}} \mathrm{ke}$ ]
(b) [fazera'male]
[fa'zer a'male]
(J.J.M.)
(c) $\left[\right.$ mari $^{\mathrm{n}} \mathrm{kres}$ 'padu]
['mar e ${ }^{\mathfrak{y} k r e s ' p a d u] ~}$
(G.J.L.)
(d) [sentiro'friw]
[sen'tir o'friw]

Seja a configuração do vocábulo "fazer", inspirada em Encrevé (1988):

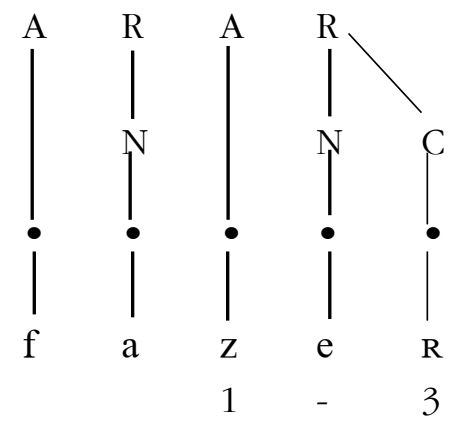

Esquema acentual 
Há opção de encadeamento em (4) (b). O esquema acentual virtual de (5), vocábulo oxítono, acusa o acento na última sílaba, recebendo a pretônica acento "1". Processando-se o encadeamento em (4) (b), por exemplo, demarca-se uma só unidade fonológica (frase ou vocábulo), modificando-se o esquema acentual. Utilizamse no texto os valores convencionados por Mattoso Câmara (1997, p. 34-39) para demarcação da tonicidade nos grupos de força. Seja:

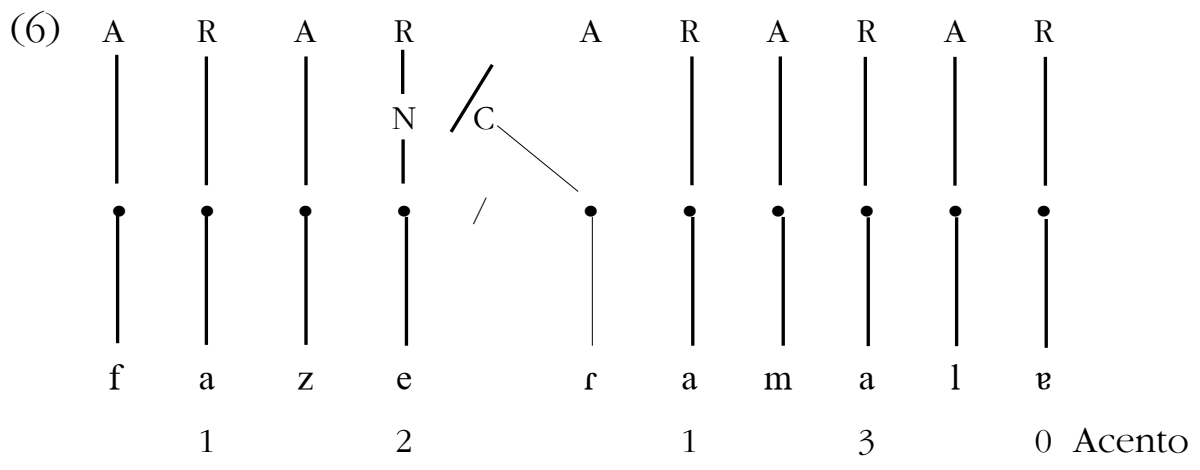

$\mathrm{O}[\mathrm{R}]$ coda flutuante, intervocálico, seguido, pois, por ataque vazio, ressilaba. Associa-se ao nó esqueletal do ataque à direita como uma batida intervocálica, reorganizando o vocábulo fonológico ao desfazer a fronteira intervocabular. Os dois vocábulos perfazem uma única unidade fonológica. O processo afeta os níveis silábico, esqueletal, segmental, sintagmático e prosódico. Em termos amplos, pode-se dizer que opera uma metátese efetivada de forma semelhante em (4) (a) (b) (c) e (d).

Delineia-se uma abertura na escala da sonoridade: a coda "CV[R]" é substituída, no esquema da líquida, por uma batida intervocálica, "V[r]V", que se encontra em nível mais elevado de sonoridade. No contexto, co-articula-se com a vogal da direita e da esquerda, num processo de assimilação de vogais bem demarcado. A classificação da vibrante como mais fechada que a batida, ambas detentoras do traço [coronal, + anterior], fundamenta-se na estrutura fonêmica. Na verdade, os dois segmentos, embora distintos, são aparentados: a vibrante compreende três ou mais batidas; e a batida, 
apenas um contato do ápice da língua com os alvéolos, determinando efeitos articulatórios e acústicos particulares. Comprove-se através de sonagrama e, diacronicamente, remonte-se à origem latina.

Quanto ao confronto relativo à abertura e sonoridade entre a vibrante líquida [dorsal] e a batida [coronal], parece pertinente uma sugestão de revisão do tema. Interfere a variável ponto de articulação que confere à vibrante recuada uma organização interna formântica mais precisa, aproximando-a da vocalidade.

Em (5), a linha tracejada indica a flutuação de coda: o segmento no léxico constitui um elemento flutuante. O léxico da língua resguarda para / $\mathrm{R} /$ uma série de realizações virtuais que facultam ao falante um desempenho lingüístico condizente com o contexto sociocultural. Os limites da flutuação se tornam muito amplos, se considerado o contexto histórico, sociopolítico, cultural. A flutuação conduz, assim, à explicação da variedade lingüística.

Ilustra-se o encadeamento através do sonagrama:

(7) [fazera'vide] (J.A.R.)

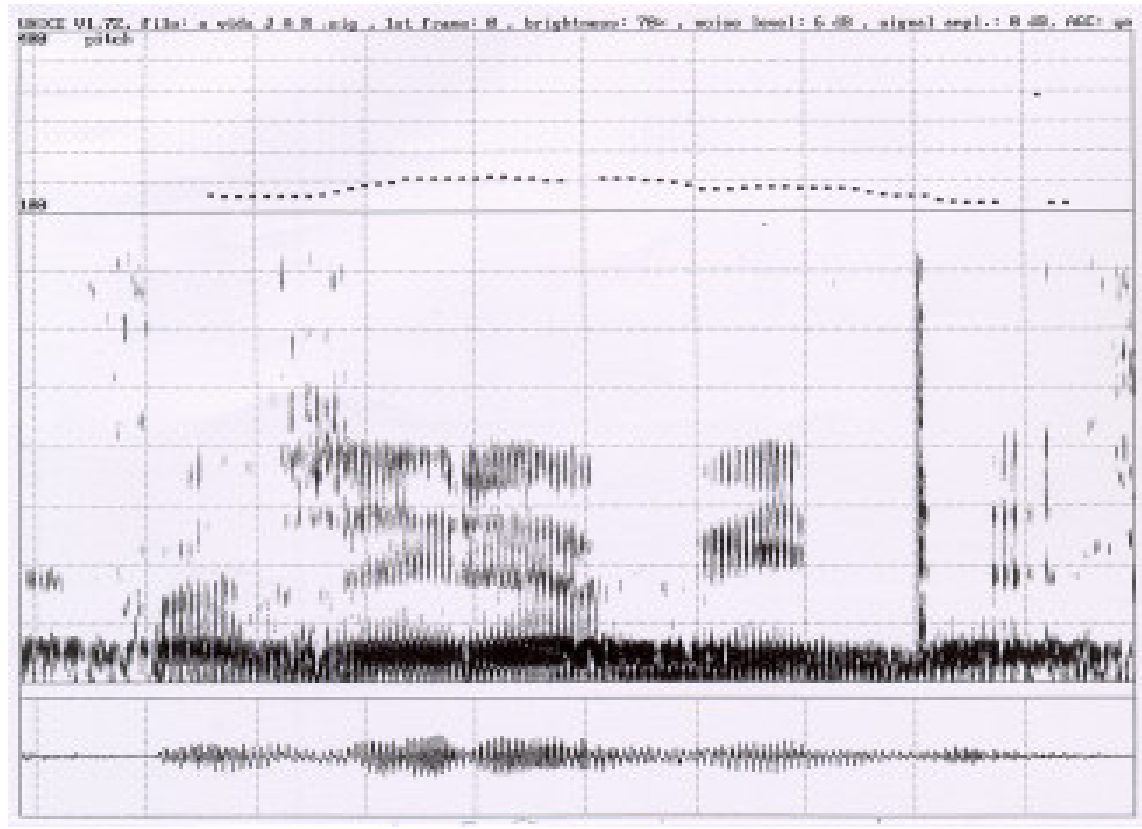


O sonagrama acusa uma simples batida entre a segunda e a terceira vogais: afirmação que pode ser corroborada através do sinal. Introduz-se uma figura, para confronto entre o encadeamento e a elipse de coda com alongamento compensatório, ilustrados através das frases:

(8) (a) [tẽỹvalo'ramigu] (J.J.M.)

(b) [tẽỹva'lo' vi'-taw] (J.J.M.)

(9)

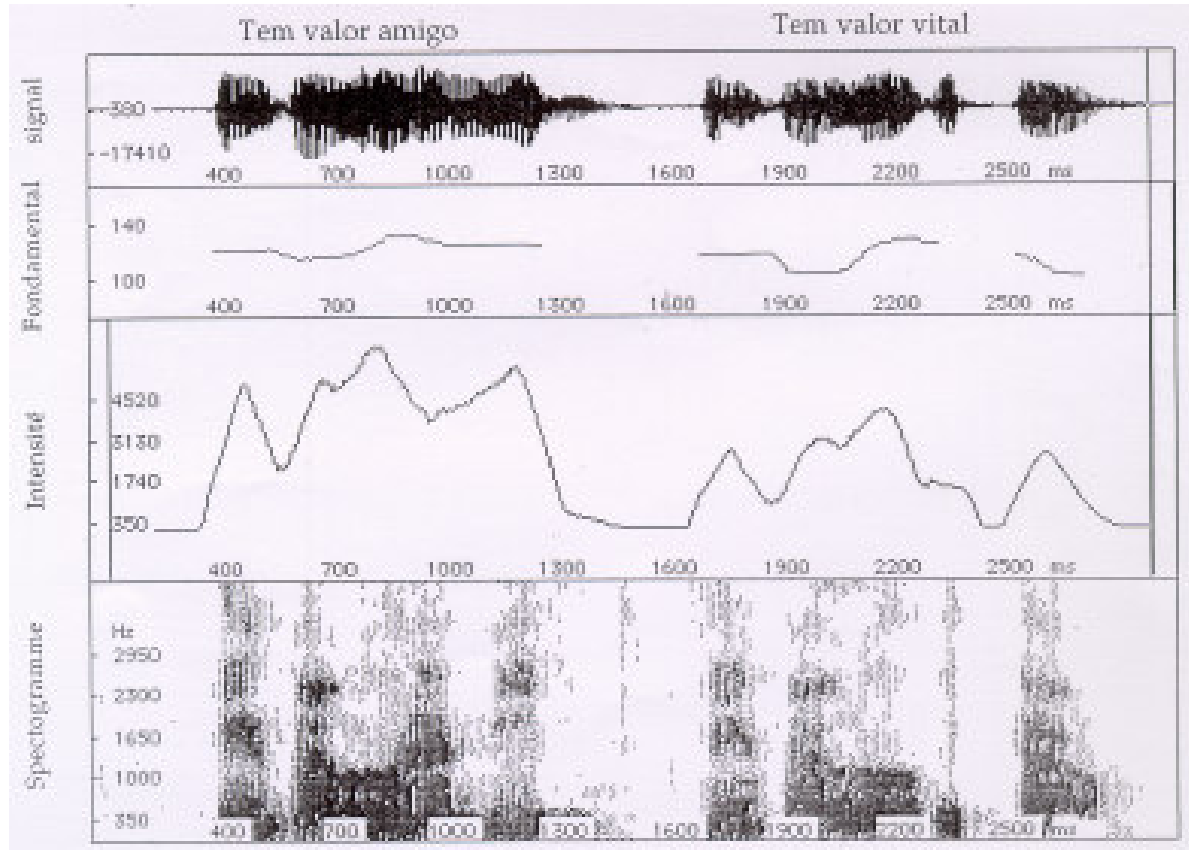

O encadeamento em "valor amigo" está demarcado no sinal, na curva do fundamental e no espectograma. Há uma continuidade nesses três níveis de configuração da frase fonológica, enquanto em [va'lo ${ }^{1}$ vitaw] a ruptura se insinua nos mesmos três níveis entre as silabas [lo] e [vi]. Pela curva da intensidade, percebe-se que o informante em (a) situa como sílaba mais acentuada da estrutura [ra], enquanto o sistema acentual virtual da língua a delimitaria em [mi]. Na frase 
(b), a elipse de [R], com alongamento compensatório produzidos facultativamente pelo falante, determina a maior incidência da intensidade em [lo], fato verificável pela duração da vogal, passando [taw] a corresponder a uma tônica virtual. Enquanto na juntura a duração não se faz pertinente, torna-se fundamental na elipse com alongamento compensatório.

A seqüência de $[R]$ coda na fronteira de vocábulo de um oxítono ou paroxítono seguido de $[R]$ no ataque inicial de vocábulo pode acarretar, na cadeia da fala, uma geminada. Já se aludiu ao fato de que o latim clássico continha geminadas no seu sistema de consoantes. No português padrão atual, não existe a verdadeira geminada como elemento constante do sistema consonântico. Pode ocorrer em alguns dialetos como característica peculiar da fala, sendo identificada, no caso, como processo facultativo da gramática dialetal.

A configuração da geminada, na teoria multilinear, prevê duas posições esqueletais e um só elemento no nível segmental (ENCREVÉ, 1988). Interprete-se como dois elementos subjacentes representados por apenas um segmento na fala concreta. Verifique-se:

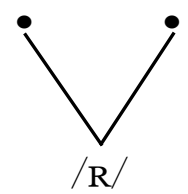

A geminada latina, sempre intervocálica, resultou numa consoante simples do português. Toda simples tinha uma correspondente geminada, como segue (SILVA, 1996, p. 77):

\section{(11) (a) $[\mathrm{pp}][\mathrm{tt}][\mathrm{kk}][\mathrm{bb}][\mathrm{dd}][\mathrm{gg}][\mathrm{ff}][\mathrm{ss}][\mathrm{mm}][\mathrm{nn}][\mathrm{II}][\mathrm{rr}]$}

Afirma Mattoso Câmara (1975, p. 51) que a geminação se estabeleceu na pré-história do latim pela aglutinação de dois morfemas ou por efeito de expressividade, como em bucca.

Vejam-se os exemplos do léxico latino e sua forma derivada do português (SILVA, 1996, p.78; ILARI, 1992, p. 83; FREIRE, 1983, p. 228): 
(11) (b)

$\begin{array}{ll}\text { suppa }>\text { sopa } & \text { seccu }>\text { seco } \\ \text { abbate }>\text { abade } & \text { vacca }>\text { vaca } \\ \text { flamma }>\text { chama } & \text { stuppa }>\text { estopa } \\ \text { caballu }>\text { cavalo } & \text { arrideo }>\text { sorrir } \\ \text { stuppa }>\text { estopa } & \text { additione }>\text { adição }\end{array}$

Katamba (1989, p.170) menciona a existência de consoantes e vogais geminadas em Luganda. No exemplo que segue, o processo consonântico ocorre no início do vocábulo. O elemento geminado, consonântico ou vocálico, desenvolve uma duração longa, preservando duas posições abstratas na linha do esqueleto. Seja:

\section{(12) (a) [t:a:la] correspondente a ttaala (lâmpada)}

Em línguas semíticas como o árabe e o hebreu, a morfologia pode comprometer a participação da geminada, modificando o padrão silábico. Para ilustrar, observe-se que o processo se define na primeira língua mencionada pela duplicação da consoante do centro do radical. A segunda consoante se comporta como uma geminada, na formação do causativo verbal (KENSTOWICZ, 1994, p. 296):

(12) (b) [šarib] 'drink' (beber) [šarrab] 'make drink' (preparar bebida)

Foram retirados do corpus do dialeto português em análise os seguintes exemplos:

(13) (a) [amoro'm $\tilde{e}^{\mathrm{n}} \mathrm{t}$ jiku] (L.M.A.)

(b) [valoro'mẽnu] 
Observe-se a configuração fonológica de (13) (a):

(14)

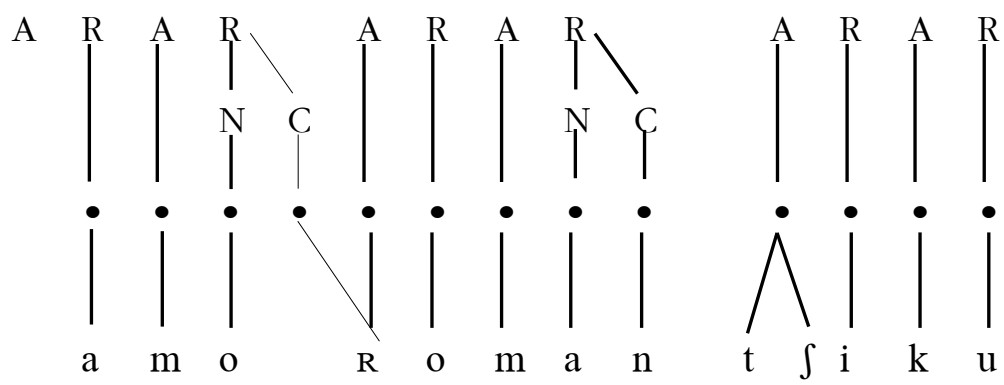

Postula-se que, em português, a geminada se concretiza, na superfície, com maiores características de ataque inicial do que de coda precedente. Resulta, pois, da fusão de coda e ataque subjacentes com proeminência da última posição na realização fonética. O fato implica uma maior duração da vibrante [dorsal], pois a consoante ocupa dois "slots" na linha esqueletal. Não é atestada pausa na fala do informante e, por conseguinte, não se registra fronteira de palavras entre os elementos do sintagma nominal. Não se comprova igualmente elipse de coda em amor, nem a seqüência de dois [R], mas a presença de uma vibrante [dorsal] de maior duração na estrutura fonética da frase, sendo acusados, na segmentação da fala, elementos acústicos de uma coda enfraquecida que interagem com a linha sonora de um ataque fortalecido. Para comprovação, mostrase a figura que segue: 
(15) (L.M.A.) [amoro'm $\left.\tilde{e}^{\mathrm{n}} \mathrm{t} \int \mathrm{iku}\right]$

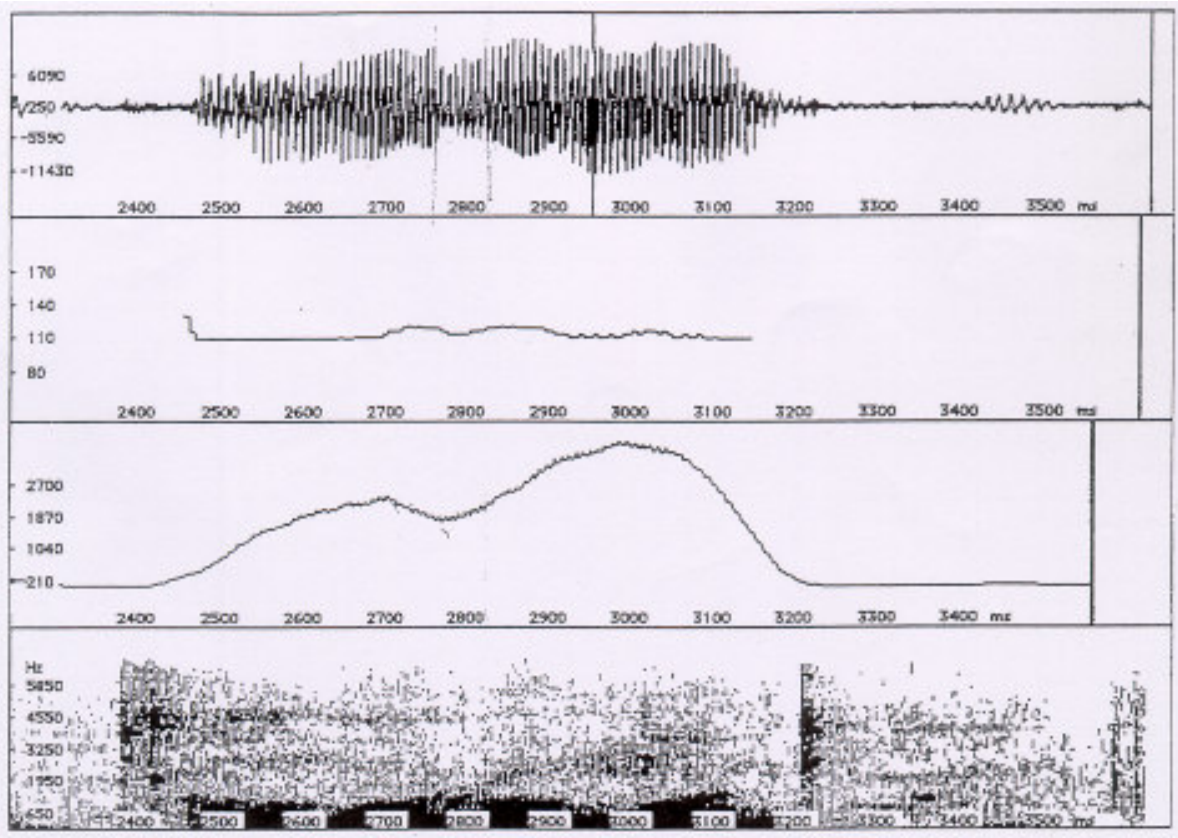

O vocábulo fonológico preserva um esquema acentual semelhante ao de um proparoxítono virtual. Na seqüência [moRo], as duas sílabas evidenciam picos de intensidade próximos. A geminada é atestada pela duração longa da vibrante intervocálica com continuidade (não há pausa) no sinal, no sonagrama e na linha do fundamental. A vibrante realiza-se como líquida dorsal.

Seja o sonagrama: 
(16) (L.M.A.) [amoro'm $\left.\tilde{e}^{\mathrm{n} t} \mathrm{jiku}\right]$ :

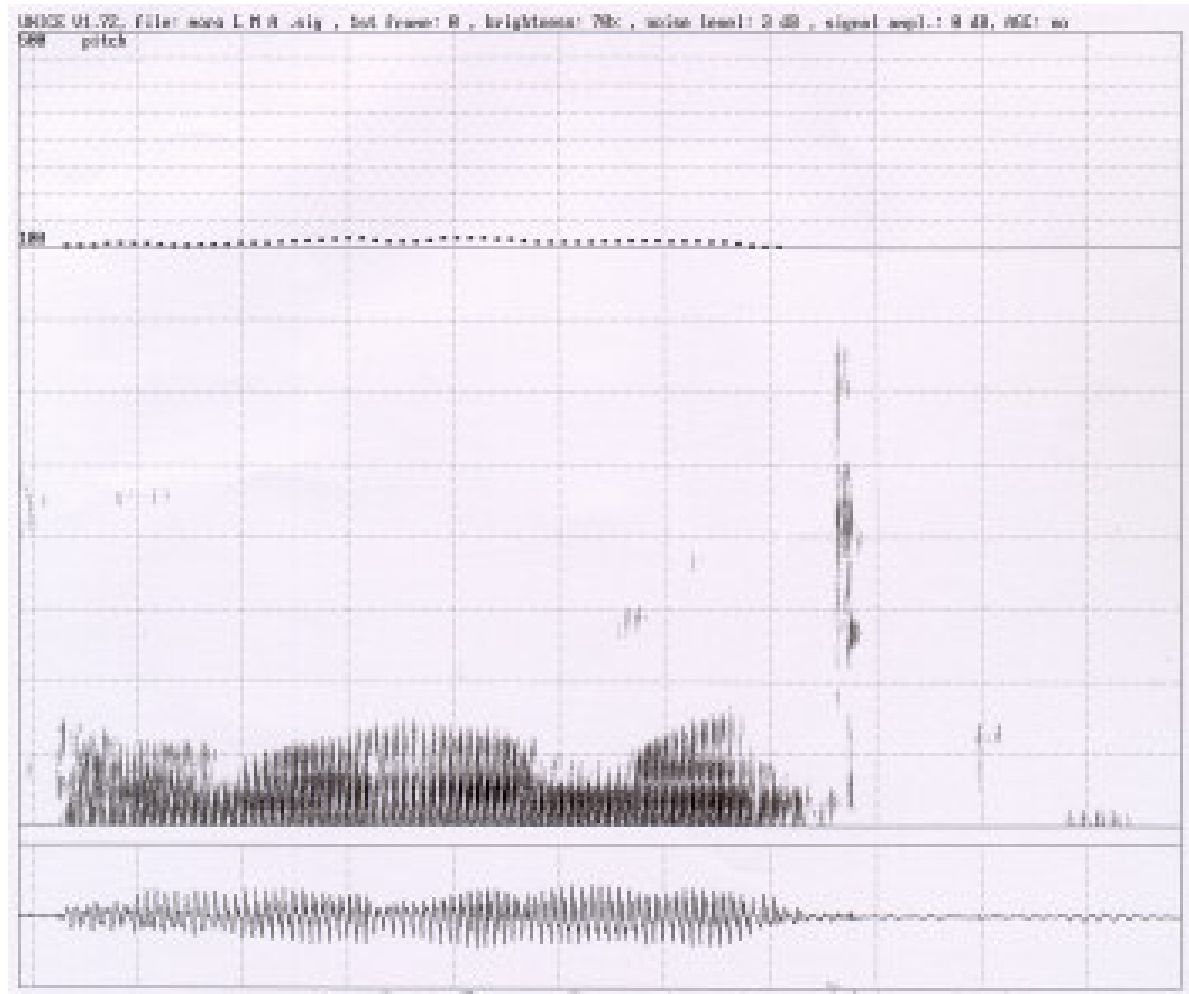

Verifica-se uma continuidade na realização de [oRo], cuja vibrante é representada por uma única líquida dorsal com duração longa. Utiliza-se o recurso do "zoom" para corroborar a estrutura da geminada. Segue-se o espectograma: 
(17) $[\mathrm{oRo}]$

UNICE U1.72 (C) LIMSI-UECSYS / file: noro L M A .sig

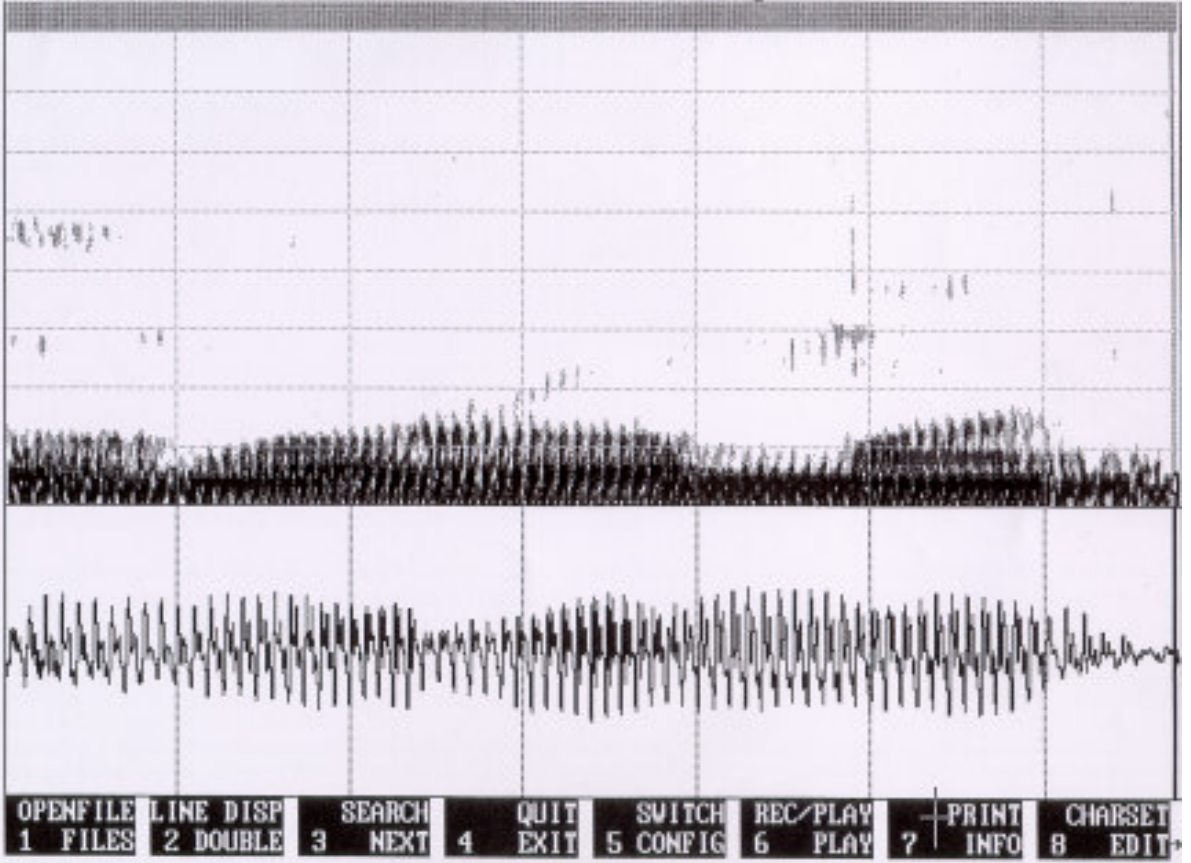

Constata-se, pois, uma unidade de duas vibrantes reunidas em uma única e não uma seqüência de dois elementos. No sinal, prevalece o elemento ataque. Acusticamente, a coda mostra-se fraca, embora perceptível, conforme o afirmado anteriormente, sobressaindo-se o ataque. Nesse sentido, prediz-se, em português, a relevância do elemento ataque na geminada vibrante dorsal líquida. Portanto, (17) confirma o esquema (14). O corpus não acusou registro da vibrante coronal para a geminada.

Conclui-se que, no dialeto do português em pauta, dois fenômenos da oralidade, o encadeamento e a geminada, sobressaemse, efetivando-se, respectivamente, através de uma batida e de uma vibrante dorsal, ambas líquidas. Situam-se no esquema "VCV" intervocabular. No primeiro caso, o "C" corresponde a uma batida e, no segundo, o "C" reúne uma coda e um ataque. A líquida 
representa o elemento mais sonoro e mais aberto no quadro consonântico do português. No seu sistema, a vibrante é mais fechada do que a batida.

Considere-se que a coda, no quadro (3), posição "7" (ponto de articulação na escala das líquidas) se caracteriza como mais fraca que o elemento vibrante do ataque silábico intervocálico. Um argumento repousa no fato de que a coda, elemento terminal silábico, representa segmento de travamento, menos audivel e menos perceptivel nessa posição, passível, pois, de um enfraquecimento, ou seja, de vocalização. Pondera-se que, cruzando as variáveis - posição silábica e ponto de articulação -, o encadeamento, realizado através de segmento coronal do ataque silábico, deve situar-se em plano menos sonoro e aberto que a geminada, que reúne coda e ataque com elemento dorsal, articulado na região posterior da cavidade bucal. No eixo vertical, referente a modo de articulação, enquadrouse, no entanto, a vibrante como menos sonora e aberta que a batida.

A partir do exposto, formulam-se três parâmetros básicos para o português:

(18) (a) o encadeamento realiza-se através da batida, na posição de ataque, tendo por base uma coda vibrante ressilabada à direita;

(b) a verdadeira geminada não pertence ao sistema consonântico padrão da língua;

(c) os processos de encadeamento e geminação recobrem fonemas pertencentes ao quadro das líquidas, que atestam o mais alto grau de sonoridade e abertura consonânticas;

(d) os processos em estudo se configuram no sistema da variação lingüística.

Seguem-se parâmetros dialetais da gramática dos pescadores de Florianópolis:

(19) (a) a vibrante, entre os pescadores, realiza-se, de modo geral, como líquida [dorsal], seguida da líquida [coronal]; especificamente na posição de coda, ocorre como líquida [dorsal] e fricativa [dorsal] e [glotal]; 
(b) a ressilabação da coda $[R]$ à direita na juntura se efetiva com maior evidência através da batida na fala regional;

(c) a geminação da vibrante [dorsal] particulariza fenômeno dialetal;

(d) a geminação se realiza através de um [R] dorsal, que, através da ressilabação à direita, reúne, na posição de ataque silábico, duas linhas de associação inseridas em duas posições esqueletais distintas: uma correspondente a coda e outra, a ataque da sílaba que lhe segue.

Neste trabalho, articulam-se princípios da teoria fonológica multilinear e premissas da fonética articulatória e acústica. O entrosamento entre as duas áreas pode contribuir para os estudos científicos, bem como para sua aplicação ao ensino.

\section{NOTA}

${ }^{1}$ Este trabalho foi apresentado pela autora no V Encontro Internacional de Lingua e Leteratura Lusófonas, realizado em 1998, em Buenos Aires, com revisões, em 2004 e 2005, para a presente publicação.

\section{REFERÊNCIAS BIBLIOGRÁFICAS}

BONNARD, Henri. Synopsis de phonétique historique. Paris: SEDES, 1982.

BRENNER, Teresinha de Moraes. Une approche multilinéaire de la variation dialectale das consonnes occlusives et fricatives chez les pêcheurs de Florianópolis. 1996. Thèse (Doctorat) - Université de la Sorbonne Nouvelle, Paris III.

CAMARA JR., J. Mattoso. História e estrutura da lingua portuguesa. Rio de Janeiro: Padrão, 1975.

CAMARA JR, J. Mattoso. Para o estudo da fonêmica portuguesa. Rio de Janeiro: Padrão, 1977.

CAMARA JR., J. Mattoso. Problemas de lingüistica descritiva. Petrópolis: Vozes, 1997.

CLEMENTS, George. The role of the sonority cycle in core syllabification. Working Papers of the Cornell Phonetics Laboratory, n. 2, April, 1988. 
CLEMENTS, George. Lieu d'articulaton des consonnes et des voyelles: une théorie unifiée. In: LAKS; RIALLAND. Architecture des représentations phonologiques. Paris: CNRS éd, 1993.

ENCREVÉ, Pierre. La liaison avec et sans enchaînement: phonologie tridimensionnelle et usages du français. Paris: Seuil, 1988.

FARIA, Ernesto. Fonética histórica do latim. Rio de Janeiro: Livraria Acadêmica, 1957.

FREIRE, António. Gramática latina. Braga: Faculdade de Filosofia, 1983.

ILARI, Rodolfo. Lingüística românica. São Paulo: Ática, 1992.

KATAMBA, Francis. An introduction to phonology. New York: Longman, 1989.

KENSTOWICZ, Michael. Phonology in generative grammar. Cambridge: Blackwell, 1994.

MALMBERG, Bertil. A fonética. Trad. Oliveira Figueiredo. Lisboa: Edição Livros do Brasil, 1954.

OLIVEIRA, Sidneya; BRENNER, Teresinha. Introdução à fonética e à fonologia da lingua portuguesa. Florianópolis: Ed. dos Autores, 1988. (ed. esgotada)

SILVA, Rosa Mattos. O português arcaico: fonologia. São Paulo: Contexto, 1996. 